\section{THE BIOCHEMICAL AND ECHOCARDIOGRAPHIC EFFECTS OF ANAEMIA OF PREMATURITY AND RED CELL TRANSFUSION ON CARDIAC FUNCTIONS IN THE VLBW INFANTS}

\author{
M.S. Saleemi ${ }^{1}$, J.D. Corcoran ${ }^{1}$, O. Franklin², \\ P. Mayne ${ }^{3}$ \\ ${ }^{1}$ Neonatology, Rotunda Maternity Hospital, \\ ${ }^{2}$ Paediatric Cardiology, Children University \\ Hospital, ${ }^{3}$ Biochemistry, Rotunda Maternity \\ Hospital, Dublin, Ireland
}

Aim: We investigated myocardial contractility as measured by Echocardiographic parameters of Tissue Doppler Imaging (TDI), Myocardial Performance Index (MPI), Ejection Fraction (EF) and Biochemical markers in VLBW infants before and after red cell transfusion.

Method:Prospective, observational study on VLBW infants of $<34$ weeks gestation and $>2$ weeks of age. Blood sampling and echocardiogram performed in 12 hours before and between 3 to 7 days after transfusion. Infants with congenital heart lesions were excluded. Data was analysed using paired t-test, Wilcoxon signed rank and Kendall's Tau to compare the differences and to see correlation between pre and post values.

Results: 74 pre and post transfusion (Pst) studies were performed on 28 infants. Pre-transfusion (Prt) haematocrit (Hct) ranged between $0.20 \%$ and $0.29 \%$.Significant improvement in each biochemical and echocardiographic parameters were seen after transfusion:

\begin{tabular}{|c|c|c|c|c|c|}
\hline \multicolumn{2}{|c|}{ TDI (cm/sec) } & \multirow{2}{*}{$\begin{array}{c}\begin{array}{c}\text { Prt } \\
\text { (Mean) }\end{array} \\
5.15\end{array}$} & \multirow{2}{*}{$\begin{array}{r}\text { SD } \\
0.79\end{array}$} & \multirow{2}{*}{$\begin{array}{c}\begin{array}{c}\text { Pst } \\
\text { (Mean) }\end{array} \\
5.57\end{array}$} & \multirow{2}{*}{$\begin{array}{r}\text { SD } \\
0.81\end{array}$} \\
\hline $\begin{array}{c}\text { Left } \\
\text { Ventricle }\end{array}$ & Systolic & & & & \\
\hline & Diastolic & 5.89 & 1.18 & 6.74 & 1.16 \\
\hline \multicolumn{2}{|c|}{ Left Ventricle(MPI) } & 0.395 & 0.1622 & 0.248 & 0.1627 \\
\hline $\begin{array}{l}\text { Biochem- } \\
\text { istry (pg/ } \\
\mathrm{ml})\end{array}$ & & & & & \\
\hline \multicolumn{2}{|c|}{ NTproBNP } & 1013 & 718.40 & 681 & 491.65 \\
\hline \multicolumn{2}{|c|}{ Troponin-T } & 54 & 17.04 & 46 & 13.50 \\
\hline
\end{tabular}

[Measurements and values]P value $<0.001$ for all readings

There was also a significant improvement in EF, septal and right ventricular contractility as assessed by TDI and MPI.
Conclusion:Assessmentofmyocardialperformance by echocardiography and biochemical markers demonstrate significant improvement following transfusion which is not proportional to the severity of the anaemia.

50

\section{CEREBRAL AUTOREGULATORY CAPACITY DURING HYPOVOLAEMIA IN NEWBORN PIGLETS}

\author{
G.H. Hahn ${ }^{1}$, C. Heiring ${ }^{2}$, O. Pryds ${ }^{3}$, G. Greisen ${ }^{1}$
}

${ }^{1}$ Department of Neonatology, National University Hospital, Rigshospitalet, Copenhagen,

${ }^{2}$ Department of Paediatrics, Hillerød Hospital, Hillerød, ${ }^{3}$ Department of Neonatology, National

University Hospital, Hvidovre Hospital, Copenhagen, Denmark

Background and aims: Hypovolaemia constitutes a stress to systemic circulation. The place of volume expansion in ill newborn infants with low arterial blood pressure (ABP) is uncertain. Our hypothesis was that hypovolaemia would further reduce cerebral autoregulatory capacity (CA-capacity) at low ABP.

Methods: Piglets ( $n=7$, age 1-2 days) were anaesthetized with propofol and randomized to normovolaemia- hypovolaemia or hypovolaemianormovolaemia. Hypovolaemia was induced by removal of $1 / 3$ of the estimated blood volume. Normovolaemia was re-established by re-infusing the removed blood volume. A resting period of 30 minutes was interpolated after removal and reinfusion of the blood volume to enable recovery of cerebral autoregulation. CA-capacity was estimated from changes in cortical flux (laser-Doppler probe) to induced rises in ABP by inflation of a thoracic aorta balloon for 30 seconds. Subsequently, CAcapacity was calculated as $\% \triangle C V R / \% \triangle A B P$ (i.e. percentage of full autoregulatory capacity), where CVR was estimated as ABP/Doppler flux.

Results: A total of 104 and 94 rises in ABP were analyzed during normo-and hypovolaemia, respectively. Hypovolaemia reduced mean $\mathrm{ABP}$ from $54 \pm 4$ to $39 \pm 5 \mathrm{mmHg}(P=0.02)$ and $C A-$ capacity from $62 \pm 9$ to $37 \pm 8 \% \quad(P=0.05)$ (mean \pm SEM). CA-capacity was $56 \pm 3$ at ABP above $40 \mathrm{mmHg}$ compared to $33 \pm 3$ below $40 \mathrm{mmHg}$ $(P=0.00005)$. Analysis of variance demonstrated an interaction between hypovolaemia and ABP such 